\title{
SUB PIXEL LOCATION IDENTIFICATION USING SUPER RESOLVED MULTILOOKING CHRIS DATA
}

\author{
${ }^{\text {a }}$.Satya Sahithi, ${ }^{\mathrm{b}}$ Shefali Agrawal. \\ ${ }^{a}$ Centre for Space Science and Technology Education in Asia and Pacific, IIRS, Dehradun, India. \\ Email: sahithi.geo@gmail.com \\ ${ }^{\mathrm{b}}$ Indian Institute of Remote Sensing, Dehradun, India. \\ Email: shefali_a@iirs.gov.in
}

Commission VIII, WG VIII/8

Keywords: CHRIS multiviewing hyperspectral images, Super Resolution Reconstruction, simple interpolation, classification, accuracy assessment, sub pixel location identification.

\begin{abstract}
CHRIS /Proba is a multiviewing hyperspectral sensor that monitors the earth in five different zenith angles $+55^{\circ},+36^{\circ}$, nadir, $-36^{\circ}$ and $55^{\circ}$ with a spatial resolution of $17 \mathrm{~m}$ and within a spectral range of $400-1050 \mathrm{~nm}$ in mode 3 . These multiviewing images are suitable for constructing a super resolved high resolution image that can reveal the mixed pixel of the hyperspectral image. In the present work, an attempt is made to find the location of various features constituted within the $17 \mathrm{~m}$ mixed pixel of the CHRIS image using various super resolution reconstruction techniques. Four different super resolution reconstruction techniques namely interpolation, iterative back projection, projection on to convex sets (POCS) and robust super resolution were tried on the -36 , nadir and +36 images to construct a super resolved high resolution $5.6 \mathrm{~m}$ image. The results of super resolution reconstruction were compared with the scaled nadir image and bicubic convoluted image for comparision of the spatial and spectral property preservance. A support vector machine classification of the best super resolved high resolution image was performed to analyse the location of the sub pixel features. Validation of the obtained results was performed using the spectral unmixing fraction images and the $5.6 \mathrm{~m}$ classified LISS IV image.
\end{abstract}

\section{INTRODUCTION}

The space borne hyperspectral remote sensing sensors monitor the earth in moderate to coarse spatial resolution. The moderate spatial resolution of these hyperspectral sensors leads to mixed pixels in the image which contain information from more than one feature on the ground. Many image processing techniques like image fusion, spectral unmixing, fuzzy classification etc., were attempted which helped in revealing the mixed pixel of the hyperspectral images. However these techniques can only give the proportion of the features within the pixel but are unable to find the location of the features within a mixed pixel. A mixed pixel captured with multiple view angles can help in resolving the features within the pixel. The multiangle imaging systems have their applications in the fields of quantification of vegetation structure, Bidirectional Reflectance Distribution Function (BRDF) model development and retrieval of geophysical parameters of agricultural crops etc. One such multi angle viewing sensor called Compact High Resolution Imaging Spectrometer (CHRIS) was launched in October, 2001 with hyperspectral capability.

CHRIS is a hyperspectral sensor of European Space Agency having multi-viewing capability with a narrow bandwidth and programmable spectral channels. It has an ability to monitor the same scene from five different zenith angles $-55^{\circ},-36^{\circ}, 0^{\circ},+36^{\circ}$, $+55^{\circ}$ with a spatial resolution of $17-36 \mathrm{~m}$ and with a spectral resolution of $18-36$ bands in the range of $400-1050 \mathrm{~nm}$. It monitors the earth in five different modes with varying spatial and spectral properties. The most commonly used mode3 is meant for landuse/landcover application having a spectral resolution of 18 bands with a spectral sampling of 2 - $3 \mathrm{~nm}$ at the blue end of the spectrum to $12 \mathrm{~nm}$ at the $1050 \mathrm{~nm}$ range and a spatial resolution of $17 \mathrm{~m}$. These multiangle viewing images can be used for resolving the mixed pixel as these incorporate additional information through the multiple views. Hence, the present work aims at constructing a $5.6 \mathrm{~m}$ high resolution image from multiangular CHRIS low resolution images using super resolution reconstruction techniques which can be used for locating the position of various features within the $17 \mathrm{~m}$ mixed pixel.

Super Resolution Reconstruction (SRR) is an image processing technique used for generating a high resolution image from the ' $n$ ' number of existing low resolution images. These low resolution images can be multi looking scenes of the same area, sub pixel shifted, aliased, blurred or decimated images of the same area or object. SRR techniques are first proposed by Tsang and Huang in 1984 in frequency domain to construct a high resolution image (HR) from several observed low resolution Landsat TM images (LR images) (Zhang et al., 2012) with subpixel displacements (Tsai and Huang, 1984). A closely related technique to SRR in spatial domain is the 'spatial interpolation technique' where the size of the image is increased using various interpolation techniques like nearest neighborhood, bicubic, cubic, spline etc. But, interpolation techniques do not use any additional information and hence result in an image with lower quality. Hence, super resolution reconstruction in spatial domain can be treated as an improved version of these where the spatial quality of the image can be improved without losing the spectral properties. The two important steps for a successful reconstruction are -1) a proper registration of the LR images and 2) establishing a proper relation between the LR and HR images. 
If $\mathrm{X}$ is the HR image, $\mathrm{Y}$ is the set of LR images, $\mathrm{N}$ is the noise vector, then the relationship between the HR image and the LR image sets can be formulated as

\section{$\mathbf{Y}=\mathbf{H X}+\mathbf{N}$}

$$
\mathrm{H}=D_{k} C_{k} F_{k} \quad, \mathrm{k}=1,2,3,4 \ldots \mathrm{n}
$$

Where $\mathrm{n}$ is the number of pixels in the image, $D_{k}$ is the sub sampling matrix, $\mathrm{C}_{\mathrm{k}}$ represents the blur matrix that represents the blurring effects that occur during the acquisition, $F_{k}$ is a warp matrix that represents the shift and rotation of the LR images.

There are various algorithms that are used for super resolution reconstruction like interpolation based, set theory based approaches, statistical regularization approaches and many others including robust super resolution technique, iterative back projection etc. The IBP technique (Kim and Bose, 1990) starts with making a rough estimate of the HR image by decimating one of the available LR images which is again down sampled to simulate the observed LR images. The difference of the observed and the simulated LR images is repeatedly back projected to minimize the initial guess until the difference is minimized. Robust super resolution (Zomet et al., 2001) is an improved version of IBP where instead of 'difference', the median of errors is back projected repeatedly along with an additional bias correction applied at the end.

Jonathan Cheung-Wai Chan et.al., (Chan) made a review on the performance of various super resolution techniques - bicubic interpolation, Non-uniform interpolation, Total Variation, POCS and IBP on CHRIS/ Proba images to obtain a 9m resolution data set and the SR enhanced data sets have been tested for classification and unmixing purposes. According to the studies made by Galbrith et.al., 2005, multiangular images with angles $>48^{\circ}$ cannot be used for super resolution reconstruction works as these require some special atmospheric corrections which when discounted can cause serious distortions. Hence, in the present work only three angular images $+36^{\circ}$, nadir and $-36^{\circ}$ are used for reconstructing the high resolution image.

\section{METHODS AND MATERIALS}

\subsection{Study area}

The study area (Fig 1) is a part of Suratgarh area of Sri Ganganagar district, Rajasthan, India. It falls under the latitude and longitude of $29^{\circ} 21^{\prime} 5.60^{\prime \prime} \mathrm{N}$ to $29^{\circ} 21^{\prime} 5.60^{\prime \prime} \mathrm{N}$ and $73^{\circ} 54^{\prime} 43$ $.50^{\prime \prime} \mathrm{E}$ to $74^{\circ} 2^{\prime} 12.06^{\prime \prime} \mathrm{E}$ with an average elevation of $174 \mathrm{~m}$ above the mean sea level. A small part of the study area which is found to be unchanged in the CHRIS and LISS IV images was considered for super resolution reconstruction. The considered area constitutes various types of agricultural crops like wheat, mustard, gram etc. and hardened sand dunes covered with scrubs.

\subsection{Materials used}

The CHRIS multiviewing sensor of ESA onboard PROBA mission is used for SRR. The high resolution LISS IV image is used for validation.

\begin{tabular}{|l|l|l|l|l|}
\hline Sensor & $\begin{array}{l}\text { Acquisiti } \\
\text { on date }\end{array}$ & $\begin{array}{l}\text { Number } \\
\text { of } \\
\text { bands }\end{array}$ & $\begin{array}{l}\text { Spatial } \\
\text { Resolution }\end{array}$ & Swath \\
\hline $\begin{array}{l}\text { CHRIS } \\
\text { (Mode } \\
3 \text { ) }\end{array}$ & $\begin{array}{l}29 \text { th } \\
\text { February, } \\
2008\end{array}$ & 18 & $17 \mathrm{~m}$ & $14 \mathrm{~km}$ \\
\hline LISS 4 & $\begin{array}{l}1 \mathrm{st} \\
\text { March, } \\
2009\end{array}$ & 3 & $5 \mathrm{~m}$ & $23 \mathrm{~km}$ \\
\hline
\end{tabular}

Table1. Datasets used for the study

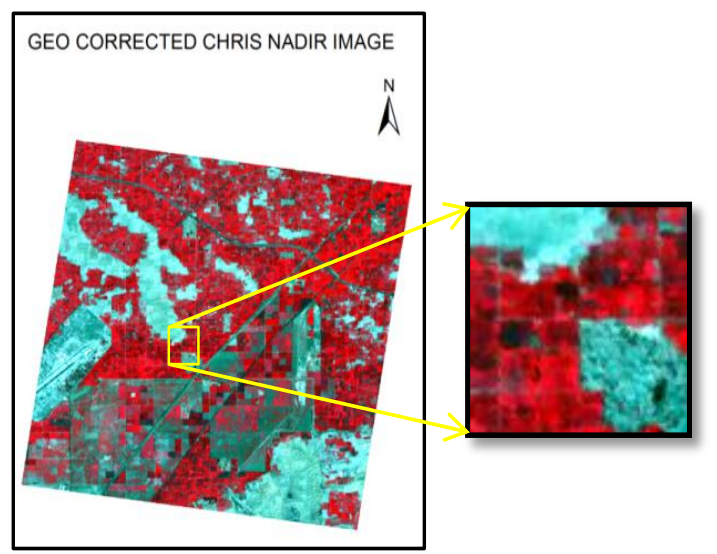

Fig 1. Study area and considered subset

The methodology adopted is shown in fig 1 .

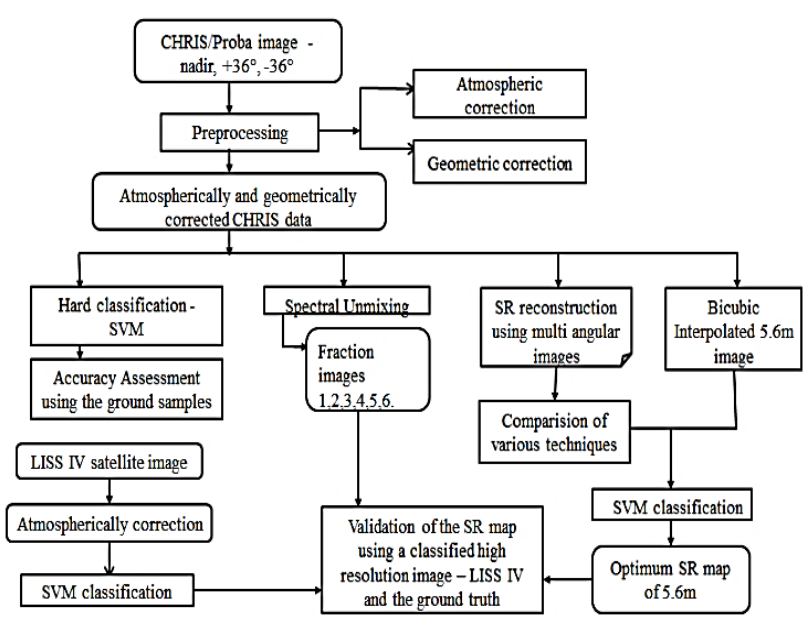

Fig 2. Methodology adopted for the present work

\section{RESULTS AND DISCUSSIONS}

The CHRIS data was radiometrically corrected for vertical stripes and unwanted noise using a weighted averaging technique and then both the CHRIS and LISS IV datasets were atmospherically corrected using model based atmospheric correction modules. The atmospherically corrected LISS IV images were geo-corrected using 26 GCP's and then used for co-registering the CHRIS nadir and angular images. 


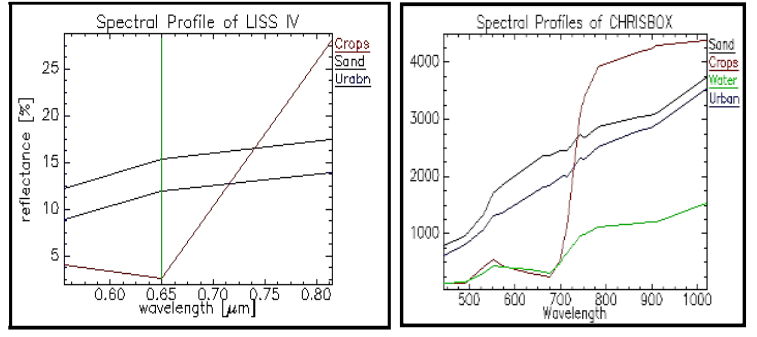

Fig 3. Atmospherically corrected profiles of CHRIS and LISS IV

\subsection{Scaling and bicubic interpolation}

Scaling and bicubic convolution are the most commonly adopted methods for increasing and reducing the size of the image. Hence, initially the image was scaled using nearest neighborhood technique and also using the bicubic interpolation was performed using the same scale factor ( $s=3$ in this study) the results of which are presented in fig 4. It was observed that the nearest neighbourhood (NN) scaling added the same value to the corresponding new 9 pixels and had crispness at the boundaries of the linear features like roads and boundaries. On the other hand, the bicubic convolution process smoothened the image and also a loss in the spectral information of the features at the boundaries was noticed due to the averaging of the surrounding 16 pixels.

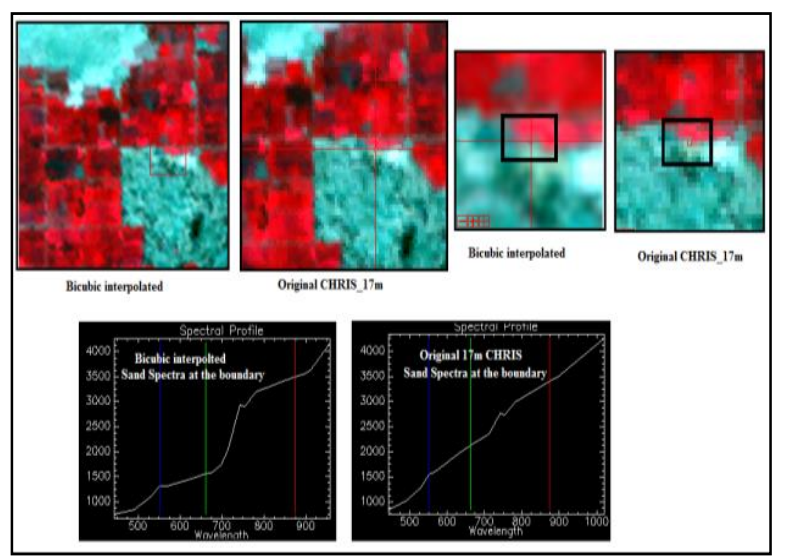

Fig 4. Spatial and Spectral observations of the bicubic interpolated image

\subsection{Super resolution reconstruction}

Super reconstruction was performed on nadir, and the two 36 angular images using four techniques - interpolation, projection onto convex sets, iterative back projection and robust super resolution techniques.

An initial automatic registration as stated by Vandewalle, 2006 was performed initially to estimate the shifts and rotations among the input low resolution images. Then the four super resolution techniques were performed which are validated using the spectral profiles and based on the classifications. The super resolved reconstructed high resolution images obtained using interpolation, IBP, POCS and robust techniques are given in Fig 5.

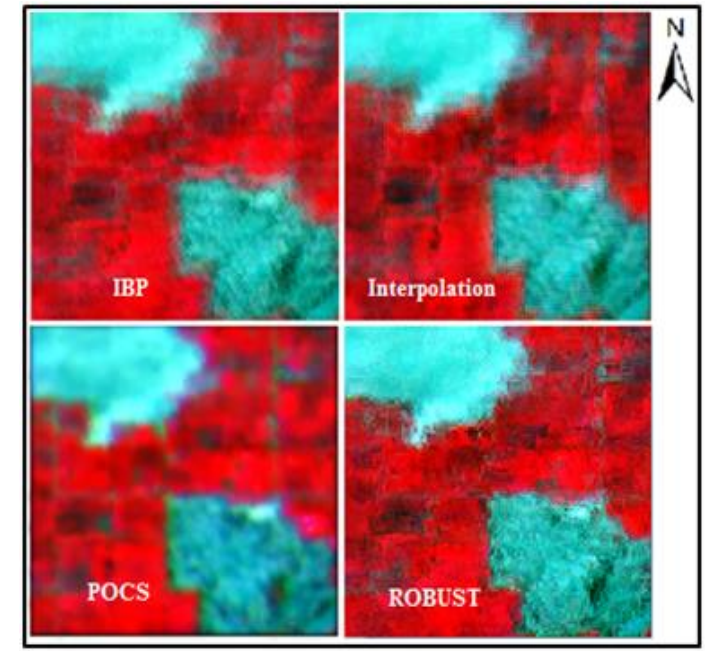

Fig 5. SR reconstructed high resolution images generated using the considered four techniques

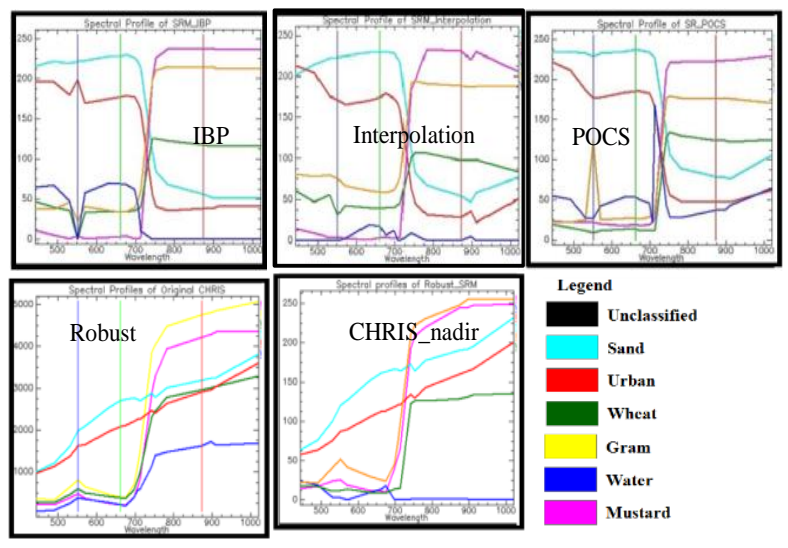

Fig 6. Spectral profile analysis of the super resolved high resolution images.

Spectral analysis was made on the super resolved images by observing the spectral profiles of features at the same geographic locations in all the four images which is shown in fig 6 . The spectral profiles of the wheat, mustard and Gram were preserved in all the four techniques but the robust super resolution technique preserved the spectral characteristics of all the features well, when compared to the other attempted SRM techniques. Also, the spectral profile of water which was not coming well in the original CHRIS due to mixed pixel effect was improved in the robust SRM image as the mixed pixel effect was revealed. However there were some minor spectral distortions observed in the profiles of robust SRM result which might be due to many factors like usage of median of the errors in the algorithm which induces some inbuilt bias to the back propagated values, registration parameters used etc.

\subsection{Classification of LR and HR images}

The CHRIS multi angular images were classified using the extracted end members. A total of 6 classes were considered and the spectral profiles were matched with collected ground spectra using spectral matching algorithms. There were certain areas in the image which were affected due to change in the look angle which also gave a noticeable change in the classification results of 
the nadir, $+36^{\circ}$ and $-36^{\circ}$ images. Certain changes observed in the classification of the CHRIS angular images are given in fig 7.

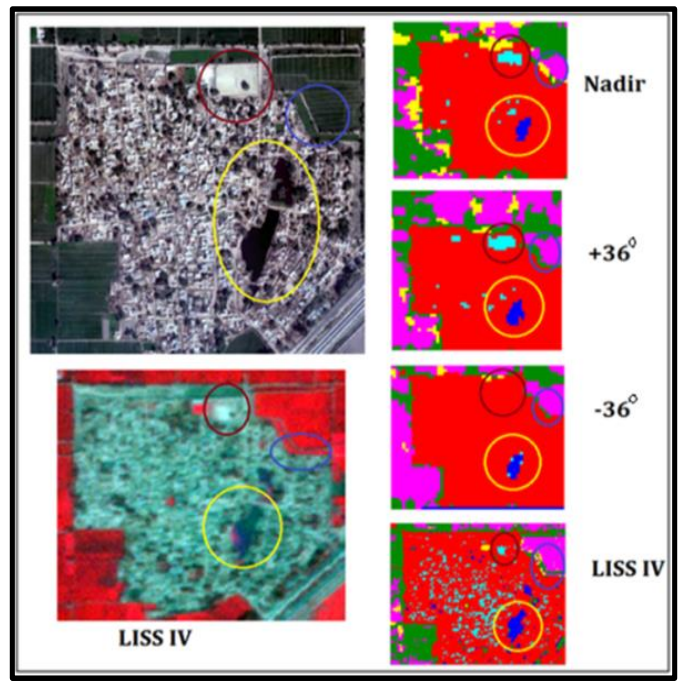

Fig 7. Classification of CHRIS $17 \mathrm{~m}$ images using SVM classifier

The obtained super resolved reconstructed high resolution images are then classified using the SVM classifier and the results are presented in fig 8. The results of SVM classification of SRR images obtained from various techniques were analyzed. It was observed that the IBP and robust techniques were giving better results while POCS was producing the least reliable landcover maps due to over smoothening effect. The interpolation based SRM results were having a noise like error over the whole image which was a drawback. Even a keen observation of IBP and Robust techniques showed that the water body, sand etc were well classified in the robust technique than the IBP results. The places with registration errors in IBP were misclassified and also the water class was noticed to be over classified.

Hence, from the analysis of spectral profiles, visual inspections and also the classification results, it was observed that the robust super resolution technique succeeded in bringing out the landcover classes which were hidden in the mixed pixels than the other SRR techniques. Accuracy assessment of the robust super resolution result classified using the SVM classifier gave an overall accuracy of $79.45 \%$. There were misclassifications found in the classes of wheat and mustard while the sand class was having $100 \%$ accuracy. The user's and producer's accuracies are presented in table 1. A comparision of producer's and user's accuracy of the classified LISS IV image and the super resolved sub pixel map has shown improvements in the classes of sand, urban and water in the SRR sub pixel classified image than the classified LISS IV map. The super resolved classified map gave an overall kappa coefficient of 0.70932 which represents a probable $71 \%$ better accuracy than the classification results that would be obtained from a random, unsupervised assignment. The kappa coefficient of LISS IV was 0.68124 which represents $68 \%$ better accuracy than random assignment.
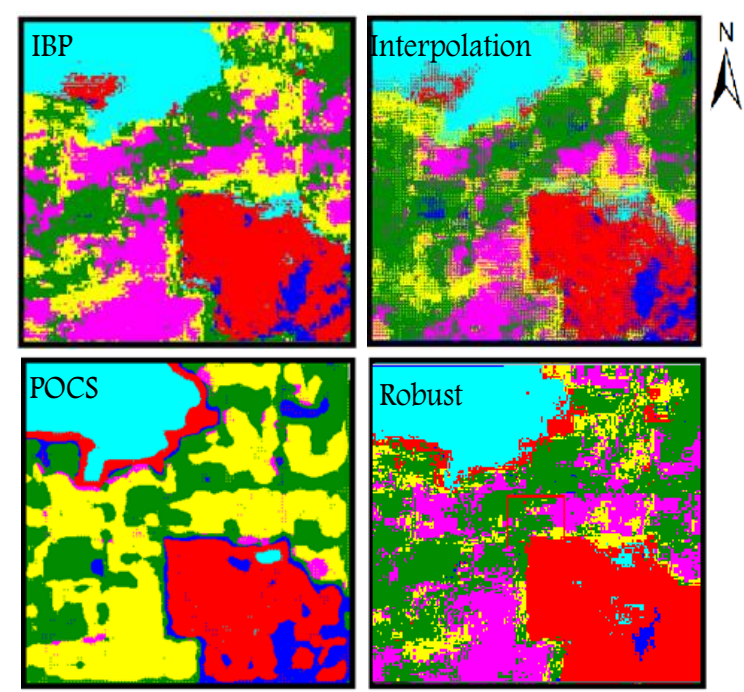

Fig 8. Classification of Super resolved reconstructed images using the SVM algorithm.

\begin{tabular}{|c|c|c|c|c|c|c|c|c|c|c|}
\hline \multirow[t]{2}{*}{$\begin{array}{l}\text { Class } \\
\text { Name }\end{array}$} & \multicolumn{2}{|c|}{$\begin{array}{l}\text { Reference } \\
\text { Totals }\end{array}$} & \multicolumn{2}{|c|}{$\begin{array}{l}\text { Classifie } \\
\text { d } \\
\text { Totals }\end{array}$} & \multicolumn{2}{|c|}{$\begin{array}{l}\text { Number } \\
\text { Correct }\end{array}$} & \multicolumn{2}{|c|}{$\begin{array}{l}\text { Producer's } \\
\text { Accuracy }\end{array}$} & \multicolumn{2}{|c|}{$\begin{array}{l}\text { User's } \\
\text { Accuracy }\end{array}$} \\
\hline & $\begin{array}{l}\mathrm{SR} \\
\mathrm{R}\end{array}$ & $\begin{array}{l}\text { LIS } \\
\text { S } \\
\text { IV }\end{array}$ & $\begin{array}{l}\mathrm{S} \\
\mathrm{R} \\
\mathrm{R}\end{array}$ & $\begin{array}{l}\text { LI } \\
\text { SS } \\
\text { IV }\end{array}$ & $\begin{array}{l}\text { SR } \\
\mathrm{R}\end{array}$ & $\begin{array}{l}\text { LI } \\
\text { S } \\
\text { S } \\
\text { I } \\
\text { V }\end{array}$ & $\begin{array}{l}\text { SR } \\
\mathrm{R}\end{array}$ & $\begin{array}{l}\text { LIS } \\
\text { S IV }\end{array}$ & SRR & $\begin{array}{l}\text { LIS } \\
\text { S IV }\end{array}$ \\
\hline Sand & 5 & 5 & 5 & 5 & 5 & 3 & $\begin{array}{l}100 \\
\%\end{array}$ & $\begin{array}{l}68.5 \\
2 \%\end{array}$ & $\begin{array}{l}100 \\
\%\end{array}$ & $60 \%$ \\
\hline $\begin{array}{l}\text { Urba } \\
\text { n }\end{array}$ & 19 & 18 & 21 & 17 & 19 & 14 & $\begin{array}{l}100 \\
\%\end{array}$ & $\begin{array}{l}77.7 \\
7 \%\end{array}$ & $\begin{array}{l}90.4 \\
8 \%\end{array}$ & $\begin{array}{l}82.3 \\
5 \%\end{array}$ \\
\hline $\begin{array}{l}\text { Must } \\
\text { ard }\end{array}$ & 17 & 18 & 15 & 15 & 10 & 14 & $\begin{array}{l}58 . \\
82 \\
\%\end{array}$ & $\begin{array}{l}88.8 \\
9 \%\end{array}$ & $\begin{array}{l}66.6 \\
7 \%\end{array}$ & $\begin{array}{l}93.3 \\
3 \%\end{array}$ \\
\hline $\begin{array}{l}\text { Whea } \\
\text { t }\end{array}$ & 24 & 22 & 24 & 20 & 17 & 15 & $\begin{array}{l}70 . \\
83 \\
\%\end{array}$ & $\begin{array}{l}81.8 \\
2 \%\end{array}$ & $\begin{array}{l}70.8 \\
3 \%\end{array}$ & $\begin{array}{l}75.0 \\
0 \%\end{array}$ \\
\hline $\begin{array}{l}\text { Wate } \\
\text { r }\end{array}$ & 2 & 3 & 3 & 4 & 2 & 2 & $\begin{array}{l}100 \\
\%\end{array}$ & $\begin{array}{l}66.6 \\
7 \%\end{array}$ & $\begin{array}{l}66.6 \\
7 \%\end{array}$ & $\begin{array}{l}50.0 \\
0 \%\end{array}$ \\
\hline Gram & 6 & 7 & 5 & 6 & 5 & 5 & $\begin{array}{l}83 . \\
33 \\
\%\end{array}$ & $\begin{array}{l}71.4 \\
3 \%\end{array}$ & $\begin{array}{l}100 \\
\%\end{array}$ & $\begin{array}{l}83.3 \\
3 \%\end{array}$ \\
\hline $\begin{array}{l}\text { Total } \\
\text { s }\end{array}$ & 73 & 73 & 73 & & 58 & & & & & \\
\hline \multicolumn{9}{|c|}{ Overall Accuracy } & $\begin{array}{l}79.4 \\
5 \%\end{array}$ & $\begin{array}{l}79.1 \\
0 \%\end{array}$ \\
\hline \multicolumn{9}{|c|}{ Kappa coefficient } & $\begin{array}{l}0.70 \\
93\end{array}$ & $\begin{array}{l}0.68 \\
12\end{array}$ \\
\hline
\end{tabular}

Table 2. Accuracy assessment - confusion matrix

\subsection{Sub pixel location identification and validations}

After classifying the robust SR reconstructed HR image, a grid of $17 \mathrm{~m} \times 17 \mathrm{~m}$ is overlaid over the $5.6 \mathrm{~m}$ classified image. Hence, each grid in this will resemble 9 pixels in the $17 \mathrm{~m}$ classified image and hence gave an improved information about the within pixel classification. Some random mixed pixels in the $17 \mathrm{~m}$ classified CHRIS image are validated using the super resolved $5.6 \mathrm{~m}$ classified map, the corresponding fractions obtained from spectral unmixing results and LISS IV (fig 10). There were also observations where the SR classified map gave better classification than the reference LISS IV classified map due to the insufficient spectral bands available in the LISS IV image. 


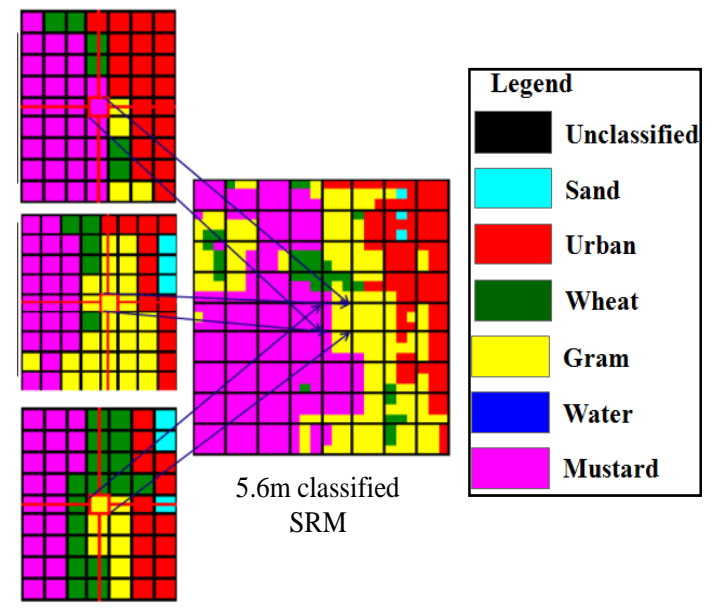

Fig 9. Sub pixel landcover map

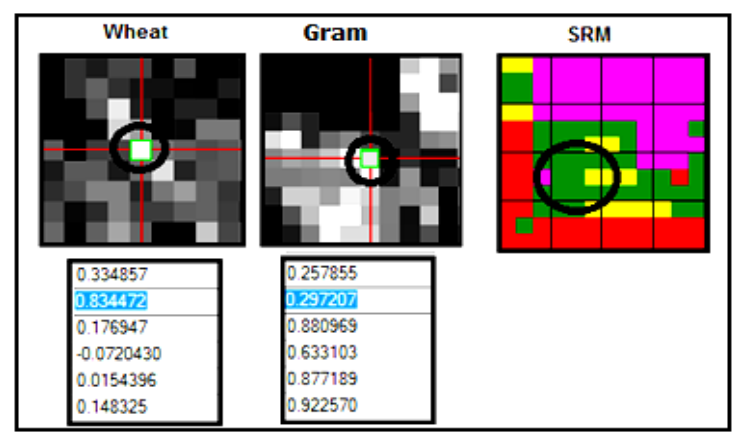

Fig 10. Sub pixel validation using fraction images

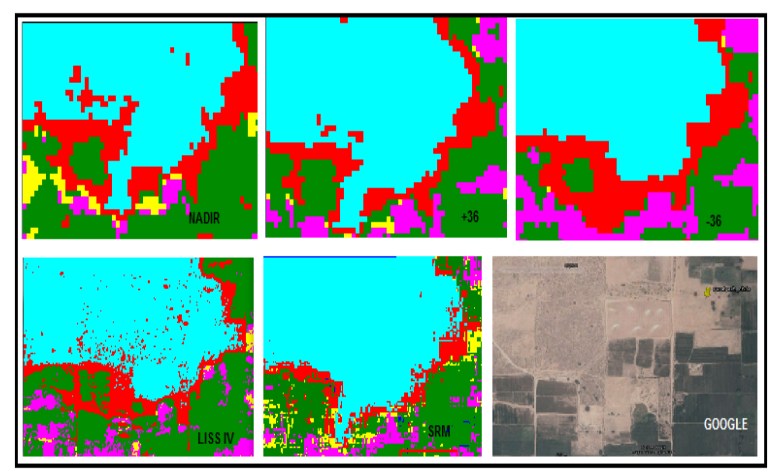

Fig 11. Improvements in the sand patch area coverage

- The patch of sand dune on the NW side of the study area appeared different in different angles which were partially agreeing with the classified LISS IV image (fig 11). The SRM map generated improved the area coverage of the sandy patch which when validated with spectral unmixing, LISS IV and Google earth images was observed to be satisfactory. The field visit of this area has strengthened the obtained result.

- The area of the water body was calculated in the CHRIS nadir image and the super resolved image which was compared with the area obtained from Google earth image of $4^{\text {th }}$ February, 2012. The area of the water body calculated from the super resolved image was much closer to the area calculated from Google earth and LISS IV classified images (fig 12). Some of the sub pixel features which were not visible in the CHRIS and LISS IV images like the trees surrounding the water body were revealed in the sub pixel map which was not observed in the
CHRIS nadir image due to mixed pixel effect. The shape index of the water body has been calculated using the formula (P/4 x sqrt(A)). (Antunes et al., 2003) and the calculated area statistics are shown in table 3 .

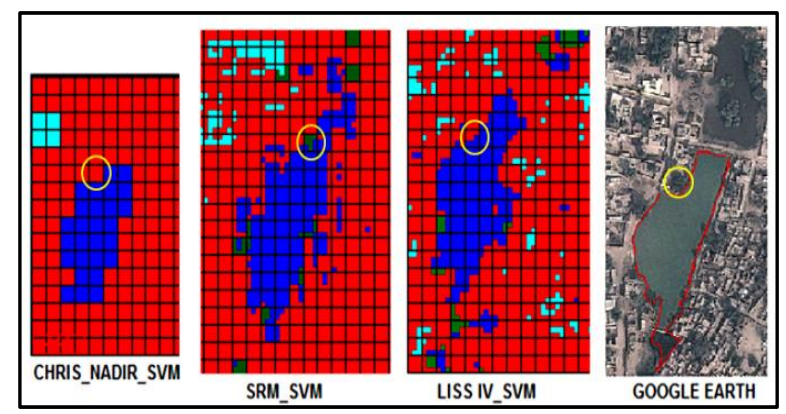

Fig 12. Validation of shape of the waterbody and certain subpixel features around the waterbody

\begin{tabular}{|l|l|l|l|}
\hline $\begin{array}{l}\text { Image } \begin{array}{c}\text { (SVM } \\
\text { classified maps) }\end{array} \\
\text { CHRIS_NADIR }\end{array}$ & Area (A) & $\begin{array}{l}\text { Perimeter } \\
\text { (P) }\end{array}$ & $\begin{array}{l}\text { Shape } \\
\text { index }\end{array}$ \\
\hline SRM & $7437.373 \mathrm{~m}^{2}$ & $452.3533 \mathrm{~m}$ & 1.577 \\
\hline LISS IV & $7688.34 \mathrm{~m}^{2} \mathrm{~m}^{2}$ & $654.214 \mathrm{~m}$ & 1.8960 \\
\hline Google Earth & $7494 \mathrm{~m}^{2}$ & 652.517 & 1.8844 \\
\hline
\end{tabular}

Table 3. Validation of shape of the water body and the shape index

\section{CONCLUSIONS}

The study strengthened that super resolution of CHRIS multiangular datasets can be suitable for sub pixel landcover map generation. The classification of the high resolution super resolved reconstructed map helped in identifying the location of the features within the $17 \mathrm{~m}$ pixel of the CHRIS image. A comparative visual, spectral and spatial analysis has shown that the robust SRR technique outperformed the other three techniques - POCS, IBP and bilinear interpolation. The scaling technique was adding the same value to the higher order grid but does not incorporate any new information which can help in improving the landcover classification. On the other hand, the bicubic convolution technique smoothened the image due to averaging of the surrounding 16 pixels which also lead to distortions in the spectral profiles of the features at the boundaries. The robust SRR technique has shown improvement in both spatial and spectral characteristics and also brought out some new information which was unavailable in the LR (low resolution) CHRIS images. The spectral profiles of water which were mixed in the $17 \mathrm{~m} \mathrm{LR}$ CHRIS images were corrected in the $5.6 \mathrm{~m}$ super resolved HR (high resolution) image which resembles the revealing of mixed pixel. A classification of the robust SRR result gave the location of the features within the $17 \mathrm{~m}$ pixel of the CHRIS which was agreeing with the results obtained from spectral unmixing and LISS IV classified map. 


\section{References}

- $\quad$ Bose, N.K., Kim, H.C., Zhou, B., 1994. Performance analysis of the TLS algorithm for image reconstruction from a sequence of undersampled noisy and blurred frames, in: Image Processing, 1994. Proceedings. ICIP-94., IEEE International Conference. IEEE, pp. 571-574.

- Chan, J.C.-W., Ma, J., Canters, F., 2008. A comparison of superresolution reconstruction methods for multi-angle CHRIS/Proba images, in: SPIE Remote Sensing. International Society for Optics and Photonics, pp. 710904710904-11.

- $\quad$ Galbraith, A.E., Theiler, J., Thome, K.J., Ziolkowski, R.W., 2005b. Resolution enhancement of multilook imagery for the multispectral thermal imager. Geoscience and Remote Sensing, IEEE Transactions on 43, 1964-1977.

- $\quad$ Kim, S.P., Bose, N.K., Valenzuela, H.M., 1990. Recursive reconstruction of high resolution image from noisy undersampled multiframes. Acoustics, Speech and Signal Processing, IEEE Transactions on 38, 1013-1027.

- Ma, J., Chan, J.C., Canters, F., 2010. Fully automatic subpixel image registration of multiangle CHRIS/Proba data. Geoscience and Remote Sensing, IEEE Transactions on 48, 2829-2839.

- $\quad$ Ma, J., Chan, J.C.W., Canters, F., 2009. Automatic image registration of multi-angle imagery for CHRIS/Proba, in: 6th EARSeL SIG IS Workshop.

- $\quad$ Ng, M.K., Koo, J., Bose, N.K., 2002. Constrained total leastsquares computations for high resolution image reconstruction with multisensors. International Journal of Imaging Systems and Technology 12, 35-42.

- $\quad$ Tsai, R.Y., Huang, T.S., 1984. Multiframe image restoration and registration. Advances in computer vision and Image Processing 1, 317-339.

- Vandewalle, P., Su, S., Vetterli, M., 2006. A frequency domain approach to registration of aliased images with application to super-resolution. EURASIP Journal on Advances in Signal Processing 2006.

- Wirawan, P.D., Maitre, H., 1999. Multi-channel high resolution blind image restoration, in: Acoustics, Speech, and Signal Processing, 1999. Proceedings., 1999 IEEE International Conference on. IEEE, pp. 3229-3232.

- Zhang, H., Zhang, L., Shen, H., 2012. A super-resolution reconstruction algorithm for hyperspectral images. Signal Processing 92, 2082-2096.

- Zomet, A., Rav-Acha, A., Peleg, S., 2001. Robust superresolution, in: Computer Vision and Pattern Recognition, 2001. CVPR 2001. Proceedings of the 2001 IEEE Computer Society Conference on. IEEE, pp. I-645-I-650 vol. 1. 